\title{
Low-dose bevacizumab induces radiographic regression of vestibular schwannomas in neurofibromatosis type 2: A case report and literature review
}

\author{
PENGFEI LIU ${ }^{1,2}$, QINGYU YAO ${ }^{1}, \mathrm{NA} \mathrm{LI}^{3}$, YONGLIANG LIU ${ }^{2}$, YUGUO WANG ${ }^{2}$, \\ MENG LI ${ }^{2}$, ZEFU LI ${ }^{2}$, JIANMIN $\mathrm{LI}^{2}$ and GANG LI ${ }^{1}$ \\ ${ }^{1}$ Department of Neurosurgery, Qilu Hospital, Shandong University, Jinan, Shandong 250012; Departments of ${ }^{2}$ Neurosurgery \\ and ${ }^{3}$ Nuclear Medicine, Binzhou Medical University Hospital, Binzhou, Shandong 256600, P.R. China
}

Received December 24, 2014; Accepted January 29, 2016

DOI: $10.3892 / \mathrm{ol} .2016 .4347$

\begin{abstract}
The current case study aimed to explore the efficacy of a low-dose bevacizumab regimen in inhibiting tumor growth and minimizing adverse effects. A 55-year-old man with neurofibromatosis type 2 (NF2) suffered bilateral vestibular schwannomas (VS) measuring 5.25 and $2.54 \mathrm{~cm}^{3}$ on the left and right, respectively. His capacity for bilateral language recognition was impaired. However, the patient refused microsurgical tumor resection and gamma knife therapy. Low-dose bevacizumab regimen $(3.3-2.2 \mathrm{mg} / \mathrm{kg}$ every 2-4 weeks) was administered by intravenous injection for $\sim 1.5$ years to inhibit tumor growth and avoid further deterioration of hearing. Compared with baseline measurements prior to treatment, the bilateral VS regressed to $3.59 \mathrm{~cm}^{3}$ $(68 \%)$ and $2.08 \mathrm{~cm}^{3}(82 \%)$ on the left and right, respectively. No hearing improvement was detected; however, the patient subjectively experienced a significant hearing improvement as his ability to communicate with people and distinguish voices was restored. No adverse effects were observed. Bevacizumab provides an alternative treatment option for those who refuse surgical intervention. Given the adverse effects commonly induced by bevacizumab, the use of a low-dose regimen would appear to be promising with regard to tumor regression and hearing preservation for patients with VS in NF2. However, the minimum dose required to sustain a response to bevacizumab in NF2 patients remains unknown. Finding the minimum effective dose sufficient to sustain hearing and/or volumetric response for individual patients is required.
\end{abstract}

Correspondence to: Dr Gang Li, Department of Neurosurgery, Qilu Hospital, Shandong University, 107 Wenhua Xi Road, Jinan, Shandong 250012, P.R. China

E-mail: doctorligang@126.com

Key words: neurofibromatosis type 2, bevacizumab, vascular endothelial growth factor, vestibular schwannomas

\section{Introduction}

Neurofibromatosis type 2 (NF2) is a rare autosomal dominant syndrome that is characterized by the presence of bilateral vestibular schwannomas (VS; acoustic neuroma). In certain patients, the disease may be complicated by meningioma, ependymoma, spinal schwannomas or vitreous opacities. The growth of VS may lead to brain stem compression, tinnitus, progressive hearing loss, deafness, ataxia and eventual mortality. The incidence of NF2 in the population is 1 in $40,000-33,000$, and $50 \%$ of the cases represent sporadic mutation, while the other half inherit the disease from their parents (1). Microsurgery for tumor resection and stereotactic radiotherapy are the standard treatment strategies; however, these may sacrifice hearing to achieve tumor control.

A vast amount of data has indicated that angiogenesis is pivotal for tumor growth, and vascular endothelial growth factor (VEGF) is a vital factor affecting angiogenesis and vascular permeability. Therefore, molecular targeted treatment may be promising for NF2-related tumors. Bevacizumab is the first Food and Drug Administration-approved monoclonal antibody that is able to neutralize the activity of VEGF in order to inhibit angiogenesis, tumor metastasis and growth, specifically (2). Bevacizumab has been used to treat malignant tumors, including metastatic rectal carcinoma and advanced non-small cell lung cancer. Plotkin et al (3) previously achieved a favorable outcome by treating NF2 with bevacizumab [5 mg/ $\mathrm{kg} / 2$ weeks; intravenous injection (IV)], including radiographic tumor regression and hearing improvement. To the best of our knowledge, the optimal regimen remains to be defined. A dosage of $5 \mathrm{mg} / \mathrm{kg} / 2$ weeks is widely used; however, this may induce adverse effects, including hypertension, thrombosis or delayed wound healing. Thus, establishing a well-tolerated therapy would be promising for patients, given the adverse effects of bevacizumab.

In the present case involving a patient with bilateral VS in NF2, a lowered dose of bevacizumab and protracted infusion interval was trialled so as to explore the efficacy of low-dose bevacizumab regimen in inhibiting tumor growth and minimizing the adverse effects. 


\section{Case report}

A 55-year-old man who was suffering with left progressive hearing loss and facial weakness was misdiagnosed with nerve deafness in 2007 at Binzhou Medical University Hospital (Binzhou, China). The patient presented right hearing loss in April 2009. On February 25, 2013, contrast-enhanced magnetic resonance imaging (MRI; Signa HDx 3.0T and 1.5T MR; GE Healthcare Life Sciences) (Fig. 1) revealed bilateral VS measuring 5.25 and $2.54 \mathrm{~cm}^{3}$ on the left and right, respectively (Fig. 1a-b). No mass effects were detected on MRI of the spinal cord. Café au lait spots $(3 \times 2 \mathrm{~cm})$ were noted in the left anterior tibial skin. The patient was conscious without nystagmus, and his left nasolabial groove was shallower than the right. These findings confirmed a diagnosis of NF2. The pure tone average (PTA) threshold of $0.5,1$ and $2 \mathrm{kHz}$ tones presented by bone-conduction indicated an impaired capacity for bilateral language recognition (Fig. 2). However, the patient refused microsurgical tumor resection and gamma knife therapy due to fears of surgery complications. On February 28, 2013, bevacizumab (Roche Diagnostics, Indianapolis, IN, USA) was administered by IV to inhibit tumor growth and avoid further deterioration of hearing initially. The drug dose was calculated according to patient's body weight (91 kg). Initially, $300 \mathrm{mg}(91 \mathrm{kgx} 3.3 \mathrm{mg} / \mathrm{kg}$ ) was administered every 2 weeks for 3 months. Subsequently, the dose of bevacizumab was gradually lowered to $2.2 \mathrm{mg} / \mathrm{kg}$ every 4 weeks in order to avoid adverse effects. Given that the patient had history of hypertension, felodipine $(5 \mathrm{mg} / \mathrm{day})$ was administered orally to maintain the patient's blood pressure within a normal range.

Following bevacizumab treatment $(3.3 \mathrm{mg} / \mathrm{kg}$, every 2 weeks) for a period of 3 months, the patient's hearing level remained stable without deterioration and the bilateral VS regressed by $56 \%$ and $76 \%$ on the left and right, respectively (Figs. 1c-d and 2). The central part of tumor was not well enhanced due to the rapid inhibition of angiogenesis by bevacizumab. On June 17, 2013, the patient was recommenced on bevacizumab ( $3.3 \mathrm{mg} / \mathrm{kg}$, every 3 weeks), administered by IV, for the next 3 months. His hearing remained stable as before and the left VS further regressed by $13 \%$, while the right VS remained stable (Figs. 1e-f and 2). Given the adverse effects induced by bevacizumab, including anemia, neutropenia and lymphocytopenia (4), on September 14, 2013, the dose was further lowered to $2.2 \mathrm{mg} / \mathrm{kg}$ and the infusion interval protracted to 4 weeks so as to reduce the risk of hypertension aggravated by bevacizumab whilst preventing tumor recurrence following drug discontinuation.

After a constant treatment $(2.2 \mathrm{mg} / \mathrm{kg})$ for 1 year, the patient's hearing was successfully preserved by low-dose bevacizumab, without further progression (Fig. 3). Although no hearing improvement was detected by pure tone audiometry (using the Madsen Midimate 622 audiometer; GN Otometrics, Taastrup, Denmark), the patient subjectively experienced a significant hearing improvement as his ability to communicate with people and distinguish voices was restored. Compared with baseline measurements prior to treatment, the bilateral VS regressed by $3.59 \mathrm{~cm}^{3}(68 \%)$ and $2.08 \mathrm{~cm}^{3}(82 \%)$ on the left and right, respectively (Fig. 1g-l; Table I). At the time of writing, the patient was continuing to
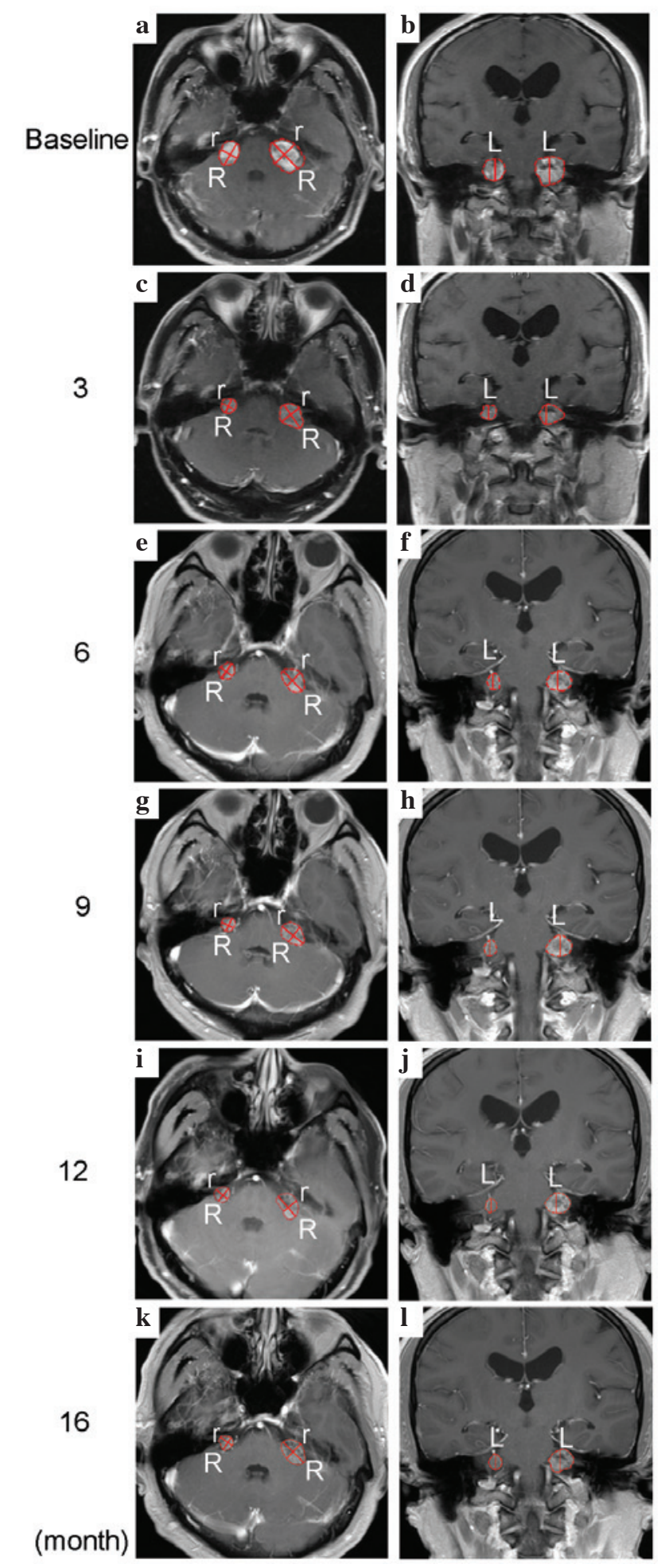

Figure 1. Bilateral vestibular schwannomas are shown in the area selected by the red line. The maximal perpendicular diameters ( $R$ and $r$ ) of the tumor were measured on axial magnetic resonance imaging scans, and the extent in the coronal direction (L) was measured on coronal scans. The total volumes (V) of the tumor were then approximated by using the formula for a spheroid: $\mathrm{V}=\mathrm{R} \times \mathrm{r} \times \mathrm{L} \times \pi / 6$. (a and c) T1WI (axial) + contrast + fat suppression; (b and d) T1WI (coronal) + contrast; (e, g, i and k) T1WI (axial) + contrast + flash; and (f, h, j and l) T1WI (coronal) + contrast + flash.

receive bevacizumab treatment $(2.2 \mathrm{mg} / \mathrm{kg}$, every 4 weeks $)$ by IV without any significant adverse effects observed, and with no signs of tumor progression or hearing deterioration. 
Table I. Tumor size analysis.

\begin{tabular}{|c|c|c|c|c|c|c|c|c|c|c|c|c|}
\hline \multirow[b]{2}{*}{ Dimension } & \multicolumn{2}{|c|}{ Baseline } & \multicolumn{2}{|c|}{3 months } & \multicolumn{2}{|c|}{6 months } & \multicolumn{2}{|c|}{9 months } & \multicolumn{2}{|c|}{12 months } & \multicolumn{2}{|c|}{16 months } \\
\hline & Left & Right & Left & Right & Left & Right & Left & Right & Left & Right & Left & Right \\
\hline $\mathrm{R}, \mathrm{mm}$ & 27.5 & 18.3 & 20.0 & 11.0 & 17.7 & 11.1 & 17.8 & 11.6 & 17.2 & 10.9 & 18.2 & 9.8 \\
\hline $\mathrm{r}, \mathrm{mm}$ & 18.7 & 15.6 & 15.1 & 10.5 & 12.1 & 10.6 & 13.4 & 10.6 & 12.6 & 10.3 & 11.3 & 9.4 \\
\hline $\mathrm{L}, \mathrm{mm}$ & 19.5 & 17.0 & 14.6 & 10.1 & 14.0 & 11.3 & 13.2 & 9.5 & 13.9 & 9.3 & 15.4 & 9.5 \\
\hline $\mathrm{V}, \mathrm{cm}^{3}$ & 5.25 & 2.54 & 2.31 & 0.61 & 1.57 & 0.70 & 1.65 & 0.61 & 1.58 & 0.55 & 1.66 & 0.46 \\
\hline
\end{tabular}

$\mathrm{R}$ / r, maximal perpendicular diameters; $\mathrm{L}$, length in coronal direction; $\mathrm{V}$, volume.

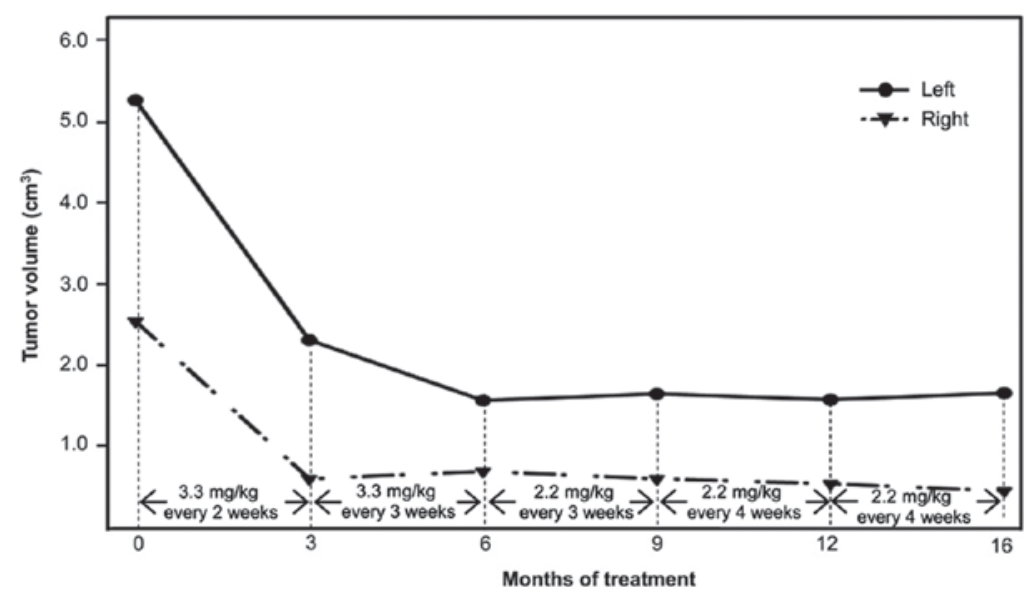

Figure 2. Compared with baseline measurements prior to treatment, the vestibular schwannomas regressed by $69 \%$ and $80 \%$ in the left and right, respectively, following bevacizumab treatment for a year.
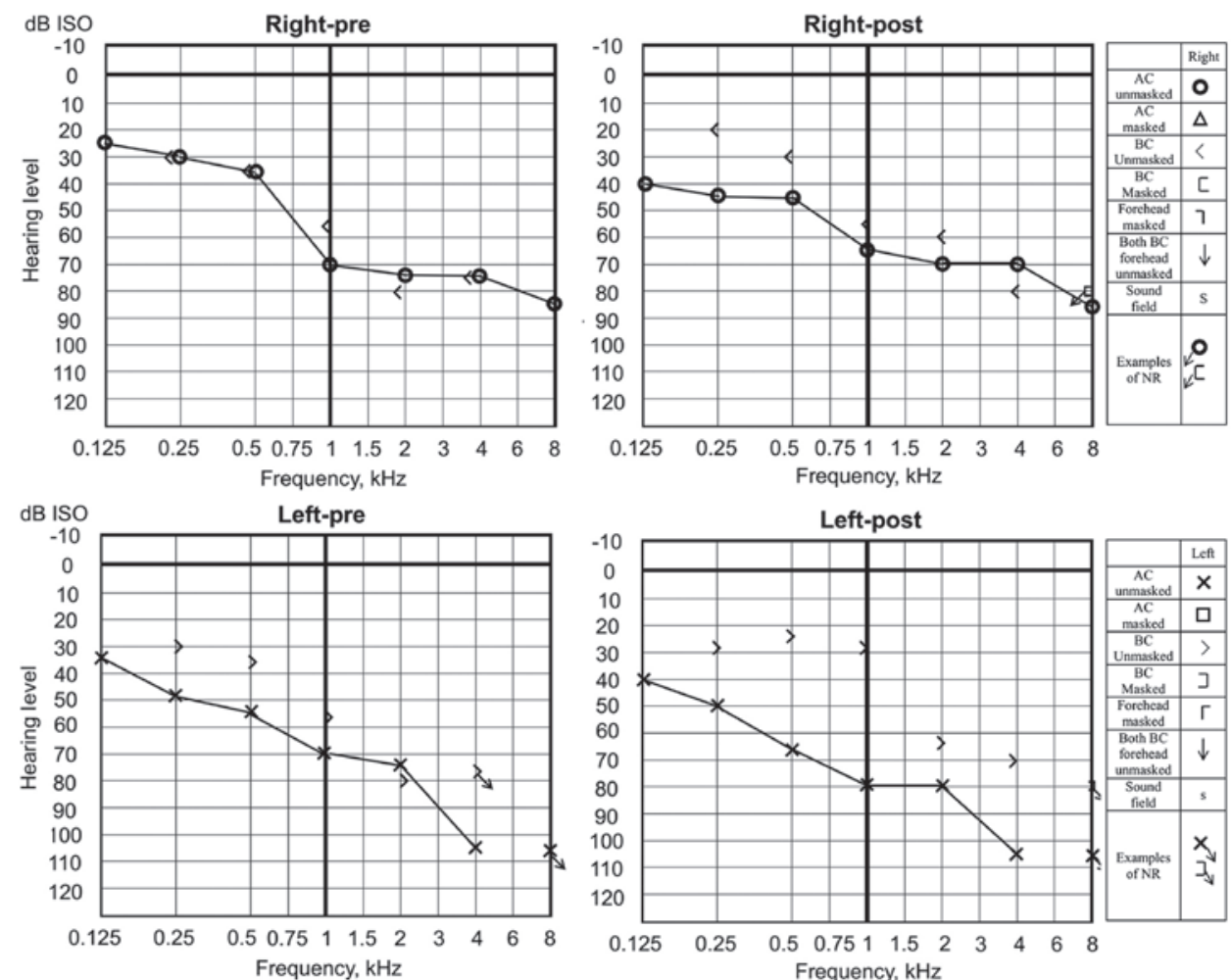

Figure 3. PTA on the right was marginally improved from $57.0 \mathrm{~dB}$ HL to $48.3 \mathrm{~dB}$ HL following bevacizumab treatment. PTA on the left was also slightly improved from $57.6 \mathrm{~dB}$ HL to $38.3 \mathrm{~dB}$ HL following treatment for a year (a PTA $<25 \mathrm{~dB}$ HL is normal for the majority of people). PTA, pure tone average; $\mathrm{dB}$ HL, decibels hearing level. AC, air conduction; BC, bone conduction; NR, no response. 
Table II. Summary of patient characteristics and adverse effects in previous studies.

\begin{tabular}{|c|c|c|c|c|c|c|}
\hline Author, year & Dose & $\begin{array}{c}\text { Patients, } \\
\mathrm{n}\end{array}$ & $\begin{array}{l}\text { Median duration } \\
\text { (range), months }\end{array}$ & $\begin{array}{c}\text { Mean age } \\
\text { (range), years }\end{array}$ & Adverse effects & Ref. \\
\hline Subbiah et al, 2012 & $5 \mathrm{mg} / \mathrm{kg} \mathrm{IV} / 2 \mathrm{wk}$ & $2^{\mathrm{a}}$ & $9.5(9-10)$ & $28.5(16-41)$ & No significant adverse effects & (5) \\
\hline Eminowicz et al, 2012 & $5 \mathrm{mg} / \mathrm{kg} \mathrm{IV} / 2 \mathrm{wk}$ & 2 & $3.5(3-4)$ & $34(31-37)$ & No significant adverse effects & (6) \\
\hline Plotkin et al, 2012 & $5 \mathrm{mg} / \mathrm{kg} \mathrm{IV} / 2 \mathrm{wk}$ & 31 & $14(6-41)$ & $26(12-73)$ & $\begin{array}{l}\text { Hypertension, proteinuria, } \\
\text { menorrhagia, epistaxis, } \\
\text { pneumonia }\end{array}$ & (7) \\
\hline Plotkin et al, 2009 & $5 \mathrm{mg} / \mathrm{kg} \mathrm{IV} / 2 \mathrm{wk}$ & 10 & $12(3-19)$ & $25(16-53)$ & $\begin{array}{l}\text { Hypertension, proteinuria, } \\
\text { menorrhagia, epistaxis, } \\
\text { pneumonia }\end{array}$ & (3) \\
\hline Mautner et al, 2010 & $5 \mathrm{mg} / \mathrm{kg} \mathrm{IV} / 2 \mathrm{wk}$ & 2 & $4.5(3-6)$ & $32(24-40)$ & No significant adverse effects & (8) \\
\hline Mautner et al, 2010 & $5 \mathrm{mg} / \mathrm{kg} \mathrm{IV} / 2-4 \mathrm{wk}$ & 2 & $15(12-18)$ & $30(22-38)$ & Hypertension & (9) \\
\hline
\end{tabular}

${ }^{a}$ Only 2 of 6 patients were treated by bevacizumab alone. IV, intravenous injection; wk, weeks.

Table III. Summary of radiological response and hearing status after the treatment.

\begin{tabular}{|c|c|c|c|c|c|c|}
\hline \multirow[b]{2}{*}{ Author, year } & \multirow{2}{*}{$\begin{array}{c}\text { Tumor reduction, } \\
\text { median (range) }\end{array}$} & \multirow{2}{*}{$\begin{array}{l}\text { No. of patients } \\
\text { experiencing } \\
\text { tumor regression }\end{array}$} & \multicolumn{3}{|c|}{ Hearing status, $\%(\mathrm{n})^{\mathrm{a}}$} & \multirow[b]{2}{*}{ Ref. } \\
\hline & & & Improved & Stable & Declined & \\
\hline Subbiah et al, 2012 & Stable & 0 of 2 & - & $100(2$ of 2$)$ & - & (5) \\
\hline Eminowicz et al, 2012 & $30.5 \%(10-52 \%)$ & 2 of 2 & - & $100(2$ of 2$)$ & - & (6) \\
\hline Plotkin et al, 2012 & $26 \%(3-91 \%)$ & 27 of 31 & 57 (13 of 23$)$ & $35(8$ of 23$)$ & $8(2$ of 23$)$ & (7) \\
\hline Plotkin et al, 2009 & $26 \%(5-44 \%)$ & 9 of 10 & $57(4$ of 7$)$ & $29(2$ of 7$)$ & $14(1$ of 7$)$ & (3) \\
\hline Mautner et al, 2010 & $42 \%(41-43 \%)$ & 2 of 2 & - & $100(2$ of 2$)$ & - & (8) \\
\hline Mautner et al, 2010 & $47.5 \%(43-52 \%)$ & 2 of $2^{c}$ & $50(1 \text { of } 2)^{d}$ & $50(1$ of 2$)$ & - & (9) \\
\hline
\end{tabular}

aPatients not eligible for a hearing response were excluded. ${ }^{\mathrm{b}}$ This is an extended follow-up study of Plotkin's previous study. ${ }^{\mathrm{c}}$ Tumor regrowth following drug discontinuation in 1 patient; tumor regression can be sustained under low-dose bevacizumab. ${ }^{\mathrm{d}} \mathrm{Hearing}$ improved during treatment but worsened following drug discontinuation.

\section{Discussion}

A complete literature review was conducted using computer search engines in PubMed (http://www.ncbi.nlm.nih. gov/pubmed) to identify all cases of VS in NF2 treated with bevacizumab. The search was performed using single or combined search terms, including 'bevacizumab', 'bilateral vestibular schwannomas', 'neurofibromatosis 2' and 'adverse effects'. In total, 6 relevant reports comprising 39 cases of VS in NF2, published between 2010 and 2014, were included (3,5-9). The clinical characteristics are summarized in Table II, including drug dose, number of patients, treatment duration, mean age and adverse effects. Radiological response and hearing status are detailed in Table III. All patients received bevacizumab $5 \mathrm{mg} / \mathrm{kg} / 2$ weeks by IV. The mean age was $26 \pm 2.2$ years (range, 12-73 years). The median duration of treatment was 12 months, and $85 \%$ of the patients (33/39) experienced tumor regression. The median tumor volume reduction was $27.5 \%$ (range, 3-91\%). The solid component regressed less than the cystic component of the tumor (8). However, the findings also indicate that tumor regrowth may occur after drug discontinuation (9). The rate of hearing improvement was 45.2\% (14/31), whilst the rate of hearing stability was $48.4 \%$ (15/31). Hearing loss was observed during treatment intermission and disappeared after treatment resumed (7). Plotkin et al (7) reported bevacizumab treatment for progressive VS in 31 patients with a 3 -year follow-up. The rates of tumor stability or regression were $88 \%$ at 1 year, $67 \%$ at 2 years and $54 \%$ at 3 years. The rates of hearing stability or improvement were $90 \%$ at 1 year, $81 \%$ at 2 years, and $61 \%$ at 3 years. However, 168 adverse events were identified during 572 patient-months of treatment. The frequency of adverse events was high, demonstrating how adverse effects have become an obstacle for the clinical use of bevacizumab.

The NF2 tumor suppressor gene has been shown to reside on chromosome $22 \mathrm{q} 12.2$, with the highest mutation rate among human genetic diseases (10). The aberration of the NF2 gene may lead to neoplasia of ectodermal and mesodermal tissues during embryonic development phases by affecting a variety of signal transduction pathways associated with tumor genesis and progression, including the phosphoinositide 3-kinase/protein kinase $\mathrm{B} /$ mammalian target of rapamycin pathway and the Raf/Ras/mitogen-activated protein kinase kinase pathway $(5,11)$. Loss of a functional NF2 gene product, Merlin (a tumor suppressor protein), may inhibit the expression 


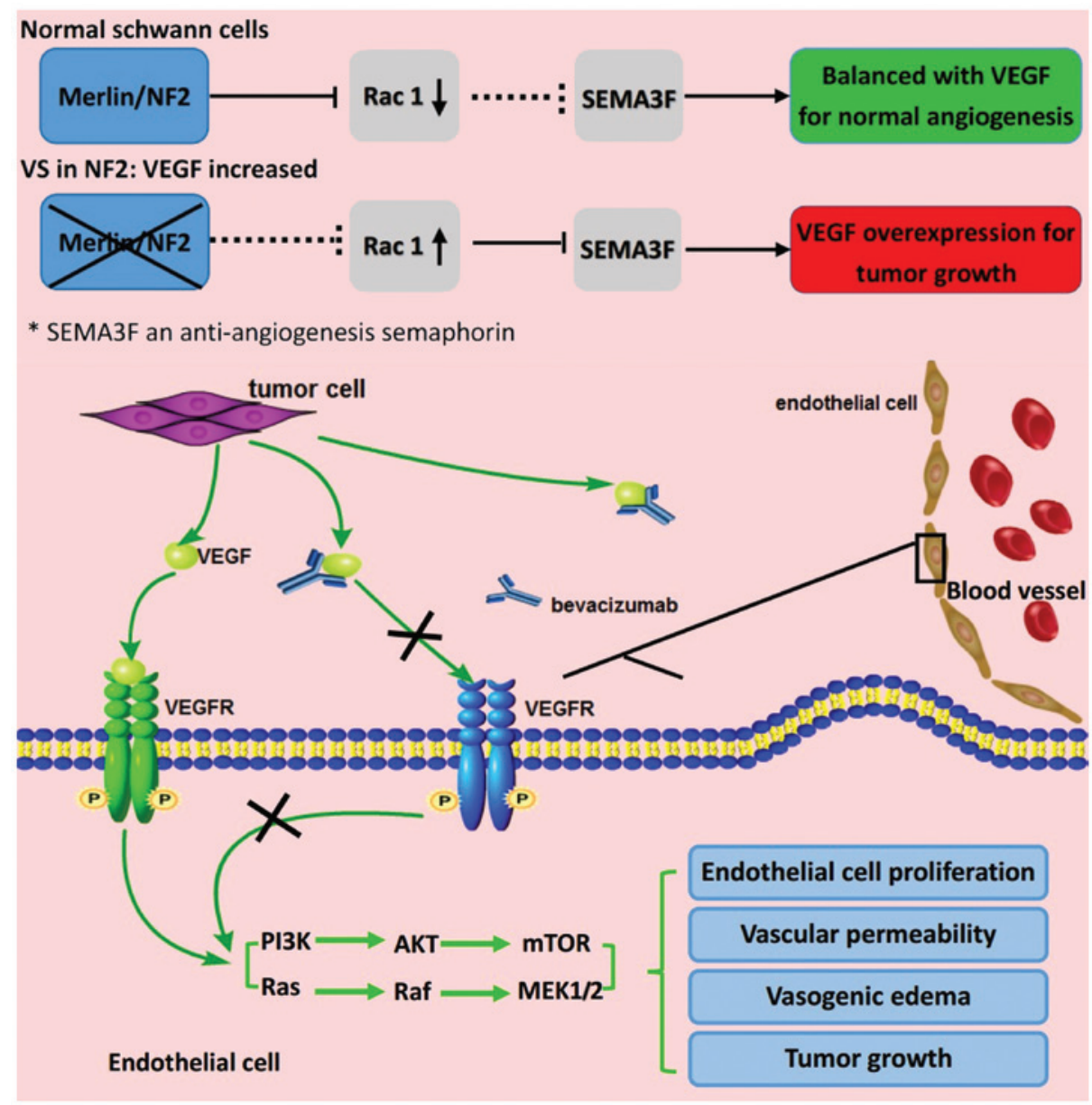

Figure 4. Mechanism underlying effect of VEGF blockade with bevacizumab on vascularity and edema. VEGF, vascular endothelial growth factor; VEGFR, VEGF receptor; NF2, neurofibromin 2; SEMA3F, semaphorin-3F; P, phosphate; PI3K, phosphoinositide 3-kinase; AKT, protein kinase B; mTOR, mammalian target of rapamycin; MEK, mitogen-activated protein kinase kinase.

of anti-angiogenesis semaphorin-3F by up regulating the Rac1 pathway in VS, resulting in a relative surplus of VEGF (12). Furthermore, tumor necrosis occurs when a tumor's blood supply cannot satisfy its growth, which may activate the compensatory overexpression of VEGF to improve the hypoxic microenvironment (12). Hence, VEGF blockade using bevacizumab may normalize the vascularity and decrease edema (Fig. 4) (12).

Microsurgery for tumor resection and stereotactic radiotherapy are usually recommended for VS in NF2 (13). However, patients must abandon hearing in order to achieve tumor control, and are also subject to possible postoperative complications, such as cerebrospinal fluid leak and facial weakness. Unfortunately, postoperative tumor recurrence may induce the need for reoperation in some patients, resulting in a decline in quality of life (14). In the current study, anti-angiogenesis therapy with bevacizumab objectively induced tumor regression and hearing preservation in a case of VS in NF2. A low-dose regimen was beneficial for avoiding significant adverse effects, providing an alternative treatment strategy instead of surgical intervention.

Compared with baseline measurements prior to treatment, the bilateral VS regressed by $3.59 \mathrm{~cm}^{3}(68 \%)$ and $2.08 \mathrm{~cm}^{3}(82 \%)$ on the left and right, respectively (Fig. 1; Table I). The absolute change in tumor volume was not as significant as the relative change; as the tumors in the current patient were not very large, a small absolute volume change may result in a large relative percentage reduction in tumor volume compared with the baseline. To avoid the potential bias in tumor volume analysis, relative percentage and absolute volume changes from baseline were used for comparison. The tumor volume remained stable in last 10 months without further regression. This suggests that tumor stability may be a compromise between tumor regression induced by low-dose regimen and tumor growth.

Although no objective hearing improvement was detected in the patient, subjective hearing improvement did occur. Furthermore, the patient's hearing declined during treatment intermission and recovered after treatment was resumed, while the tumor volume remained stable. Thus, we hypothesized that hearing stability was drug-dependent. It is possible that higher-dose regimens may be helpful for hearing improvement, whilst low-dose regimens are not. In addition, the biological mechanisms underlying the effects of bevacizumab for hearing stability may be different from those for tumor regression, which have been reported previously (15).

Whether bevacizumab may be used for long-term treatment remains controversial due to the risk of adverse effects, which include hypertension, proteinuria, thrombosis and hemorrhage (7). Furthermore, considering tumor recurrence following drug discontinuation (9), the optimal dose and duration of treatment is undetermined. As reported by Zuniga et al (16), disease recurrence and more aggressive progression were also 
detected in the treatment of malignant glioma following bevacizumab discontinuation. However, no evidence has indicated that bevacizumab discontinuation leads to accelerated disease progression. Therefore, the current patient is undergoing close monitoring to observe the efficacy of low-dose regimen in avoiding severe adverse effects and tumor recurrence following drug discontinuation.

Given the adverse effects induced by systemic IV administration of bevacizumab and the insufficient drug concentration at the tumor site due to the blood-tumor barrier (BTB), Riina et al (17) reported a novel approach involving super-selective intra-arterial cerebral infusion of bevacizumab following BTB disruption. Of 3 patients, 1 experienced tumor regression of $11 \%$ and $19 \%$ on the left and right, respectively. All 3 patients presented hearing improvement or stability. Appropriate cerebrovascular interventional therapy may be better in certain circumstances. For example, with regard to local chemotherapy, cerebrovascular interventional therapy results in less neurotrauma than craniotomy. Furthermore, cerebrovascular interventional therapy may benefit patients exhibiting tumors which extend into the internal auditory canal, as gross total resection is difficult, patients that cannot tolerate the adverse effects induced by systemic chemotherapy, and patients with a Karnofsky performance scale score of $\geq 60$ (18).

As the pathogenesis of NF2 depends on multiple signaling pathways, the combination of bevacizumab with other molecular targeted drugs, such as erlotinib and lapatinib (inhibitors of epidermal growth factor receptor), may generate synergistic effects $(5,19)$. However, the efficacy of this treatment must be confirmed by clinical trials containing a larger cohort of patients.

For the patients who exhibit no response to bevacizumab, a surgical intervention is recommended following a 4-6-week drug metabolism phase to minimize the risk of postoperative hemorrhage and delayed wound healing $(6,8)$.

In summary, a low-dose regimen of bevacizumab (2.2 $\mathrm{mg} / \mathrm{kg} / 4$ weeks, IV) would appear to be promising for patients with VS in NF2, given the adverse effects triggered by bevacizumab (4). However, the minimum dose required to sustain a response to bevacizumab in NF2 patients is still unknown, and may differ from patient to patient. Finding the minimum effective dose for individual patients sufficient to sustain hearing and/or volumetric response would aid in decreasing toxicity and long-term tolerability. With the scientific advancements, more comprehensive and safe regimens may be determined.

\section{Acknowledgements}

The authors would like to thank Dr Shilei Ni from the Department of Neurosurgery, Qilu Hospital (Jinan, China) for the valuable suggestions on study design.

\section{References}

1. Di Maio S, Mrak G, Juric-Sekhar G, Born D, Mantovani A and Sekhar LN: Clinicopathologic assay of 15 tumor resections in a family with neurofibromatosis type 2. J Neurol Surg B Skull Base 73: 90-103, 2012.
2. Claudio PP, Russo G, Kumar CA, Minimo C, Farina A, Tutton S, Nuzzo G, Giuliante F, Angeloni G, Maria V, et al: pRb2/p130, vascular endothelial growth factor, p27 (KIP1) and proliferating cell nuclear antigen expression in hepatocellular carcinoma: Their clinical significance. Clin Cancer Res 10: 3509-3517, 2004.

3. Plotkin SR, Stemmer-Rachamimov AO, Barker FG II, Halpin C, Padera TP, Tyrrell A, Sorensen AG, Jain RK and di Tomaso E: Hearing improvement after bevacizumab in patients with neurofibromatosis type 2. N Engl J Med 361: 358-367, 2009.

4. Yonezawa S, Miwa K, Shinoda J, Nomura Y, Asano Y, Nakayama N, Ohe N, Yano H and Iwama T: Bevacizumab treatment leads to observable morphological and metabolic changes in brain radiation necrosis. J Neurooncol 119: 101-109, 2014.

5. Subbiah V, Slopis J, Hong DS, Ketonen LM, Hamilton J, McCutcheon IE and Kurzrock R: Treatment of patients with advanced neurofibromatosis type 2 with novel molecularly targeted therapies: From bench to bedside. J Clin Oncol 30: e64-e68, 2012

6. Eminowicz GK, Raman R, Conibear J and Plowman PN: Bevacizumab treatment for vestibular schwannomas in neurofibromatosis type two: Report of two cases, including responses after prior gamma knife and vascular endothelial growth factor inhibition therapy. J Laryngol Otol 126: 79-82, 2012.

7. Plotkin SR, Merker VL, Halpin C, Jennings D, McKenna MJ, Harris GJ and Barker FG II: Bevacizumab for progressive vestibular schwannoma in neurofibromatosis type 2: A retrospective review of 31 patients Otol Neurotol 33: 1046-1052, 2012.

8. Mautner VF, Nguyen R, Kutta H, Fuensterer C, Bokemeyer C, Hagel C, Friedrich RE and Panse J: Bevacizumab induces regression of vestibular schwannomas in patients with neurofibromatosis type 2. Neuro Oncol 12: 14-18, 2010.

9. Mautner VF, Nguyen R, Knecht R and Bokemeyer C: Radiographic regression of vestibular schwannomas induced by bevacizumab treatment: Sustain under continuous drug application and rebound after drug discontinuation. Ann Oncol 21: 2294-2295, 2010.

10. Ferrer M, Schulze A, Gonzalez S, Ferreiro V, Ciavarelli P, Otero J, Giliberto F, Basso A and Szijan I: Neurofibromatosis type 2: Molecular and clinical analyses in argentine sporadic and familial cases. Neurosci Lett 480: 49-54, 2010.

11. Akhmametyeva EM, Mihaylova MM, Luo H, Kharzai S, Welling DB and Chang LS: Regulation of the neurofibromatosis 2 gene promoter expression during embryonic development. Dev Dyn 235: 2771-2785, 2006.

12. London NR and Gurgel RK: The role of vascular endothelial growth factor and vascular stability in diseases of the ear. Laryngoscope 124: E340-E346, 2014.

13. Carlson ML, Tveiten OV, Driscoll CL, Goplen FK, Neff BA, Pollock BE, Tombers NM, Castner ML, Finnkirk MK, Myrseth E, et al: Long-term quality of life in patients with vestibular schwannoma: An international multicenter cross-sectional study comparing microsurgery, stereotactic radiosurgery, observation, and nontumor controls. J Neurosurg 122: 833-842, 2015.

14. Narita Y: Drug review: Safety and efficacy of bevacizumab for glioblastoma and other brain tumors. Jpn J Clin Oncol 43: 587-595, 2013.

15. Fisher LM, Doherty JK, Lev MH and Slattery WH: Concordance of bilateral vestibular schwannoma growth and hearing changes in neurofibromatosis 2: Neurofibromatosis 2 natural history consortium. Otol Neurotol 30: 835-841, 2009.

16. Zuniga RM, Torcuator R, Jain R, Anderson J, Doyle T, Ellika S, Schultz L and Mikkelsen T: Efficacy, safety and patterns of response and recurrence in patients with recurrent high-grade gliomas treated with bevacizumab plus irinotecan. J Neurooncol 91: 329-336, 2009.

17. Riina HA, Burkhardt JK, Santillan A, Bassani L, Patsalides A and Boockvar JA: Short-term clinico-radiographic response to super-selective intra-arterial cerebral infusion of bevacizumab for the treatment of vestibular schwannomas in neurofibromatosis type 2. Interv Neuroradiol 18: 127-132, 2012.

18. Burkhardt JK, Riina HA, Shin BJ, Moliterno JA, Hofstetter CP and Boockvar JA: Intra-arterial chemotherapy for malignant gliomas: A critical analysis. Interv Neuroradiol 17: 286-295, 2011.

19. Lim SH, Ardern-Holmes S, McCowage G and de Souza P: Systemic therapy in neurofibromatosis type 2. Cancer Treat Rev 40: 857-861, 2014. 